\title{
Reducing Unnecessary Nitric Oxide Use: A Hospital-Wide, Respiratory Therapist-Driven Quality Improvement Project
}

\author{
Colin M Rogerson, Alvaro J Tori, Acrista J Hole, Elizabeth Summitt, Jayme D Allen, \\ Samer Abu-Sultaneh, and Kevin M Valentine
}

\begin{abstract}
BACKGROUND: We sought to evaluate the institutional use of inhaled nitric oxide (INO) and to create a pathway to reduce waste using the Institute for Healthcare Improvement's model for improvement. Our aim was to reduce the use of INO by $20 \%$ within 8 months. METHODS: This was a prospective, respiratory therapist-driven, quality improvement project. We implemented a hospital-wide INO utilization protocol that was developed by neonatology, pediatric critical care, cardiac critical care, and respiratory therapy. INO use and respiratory therapist input for protocol failures were derived from the electronic medical record and were used to generate improvement opportunities. Monthly total hospital use of INO (in hours) was used as the primary outcome measure. Median hourly use per subject (evaluated in groups of 7 subjects) was used as a secondary outcome measure. New sildenafil dosing was tabulated for pre- and post-INO weaning protocol intervention as a balancing measure. Subjects included all patients in the hospital who were given INO therapy during the specified timeframe. RESULTS: Hospital-wide total hours were reduced from $1,515 \mathrm{~h} /$ month to $930 \mathrm{~h} / \mathrm{month}$. This hospital-wide reduction of $39 \%$ equates to a costavoidance of approximately $\$ 912,000$ per year based on 2018 costs of INO of \$130 per hour. Median hours of INO per subject decreased from $88 \mathrm{~h}$ to $50 \mathrm{~h}$. Sildenafil was started in 18 of 98 subjects $(18 \%)$ in the pre-intervention period and in 12 of 109 subjects $(11 \%)$ in the post-intervention period $(P=.27)$. CONCLUSIONS: A hospital-wide, multi-professional initiative led to a reduction in unnecessary INO use, resulting in decreased subject exposure and associated cost avoidance. Key words: intensive care; costs and cost analysis; collaborative learning; quality improvement; respiratory therapy; nitric oxide. [Respir Care 2021;66(1):18-24. (C) 2021 Daedalus Enterprises]
\end{abstract}

\section{Introduction}

Inhaled nitric oxide (INO) is a potent vasodilator that critical care teams leverage to reduce pulmonary vascular resistance. There are a multitude of clinical conditions in

\footnotetext{
Drs Rogerson, Tori, Abu-Sultaneh, and Valentine are affiliated with the Department of Pediatrics, Division of Pediatric Critical Care Medicine, Indiana University School of Medicine and Riley Hospital for Children at IU Health, Indianapolis Indiana. Ms Hole and Ms Summitt are affiliated with the Department of Respiratory Care Services, Riley Hospital for Children at Indiana University Health, Indianapolis, Indiana. Dr Allen is affiliated with the Department of Pediatrics, Division of Neonatal-Perinatal Medicine, Indiana University School of Medicine and Riley Hospital for Children at IU Health, Indianapolis Indiana.
}

Dr Rogerson presented a version of this paper at the 49th Annual Meeting of the Society of Critical Care Medicine, held February 16-19, 2020, in Orlando, Florida. which reducing pulmonary vascular resistance may augment pulmonary blood flow and optimize ventilation-perfusion matching and improve oxygenation. ${ }^{1}$ For over 2 decades now, multiple studies have attempted to show improved outcomes in pediatric subjects with heart or lung diseases including ARDS, bronchopulmonary dysplasia, and pulmonary hypertension who were treated with INO. ${ }^{2-7}$

\footnotetext{
The authors have disclosed no conflicts of interest.

Supplementary material related to this paper is available at http://www. rcjournal.com.

Correspondence: Colin M Rogerson MD, Department of Pediatrics, Division of Pediatric Critical Care Medicine, Riley Hospital for Children at Indiana University Health, 705 Riley Hospital Dr, Indianapolis, Indiana 46202.E-mail: crogerso@iupui.edu.
}

DOI: $10.4187 /$ respcare. 08347 
Despite the lack of conclusive evidence regarding its efficacy for certain conditions, INO is commonly used in

See the Related Editorial on Page 175

ICUs. INO is an expensive medication that does have toxicity associated with its use. ${ }^{8,9}$ For these reasons, quality improvement initiatives have been created and protocols implemented for the initiation and weaning of INO. ${ }^{9-13}$ While there is no nationally accepted and validated weaning protocol, many of these studies showed that implementing a weaning protocol was safe and effectively decreased the duration of nitric oxide therapy and decreased its associated costs. These studies were performed in single, isolated, neonatal, pediatric, or cardiac ICUs and were often physician-driven.

The aim of this multi-professional, respiratory therapistdriven, hospital-wide quality improvement project was to reduce INO use by $20 \%$ within 8 months after protocol implementation.

\section{Methods}

\section{Study Setting and Subjects}

This study was performed at Riley Children's Hospital at Indiana University Health, a large, academic, quaternary children's hospital in Indianapolis, Indiana. The study was reviewed and exempted by the Indiana University institutional review board as a quality improvement project prior to implementation. The study was implemented in the neonatal ICU, pediatric PICU, and pediatric cardiac ICU. Each of the units has a separate intensive care physician group and respiratory therapy team, although some members of the respiratory therapy team overlap unit coverage. Extracorporeal membrane oxygenation can be performed in all 3 ICUs if needed. Any patient regardless of age or underlying condition who was started on INO therapy in any of the ICUs was eligible for the respiratory therapistdriven INO weaning protocol. All subjects received acute INO therapy through an endotracheal tube while mechanically ventilated or with a heated, humidified, high-flow nasal cannula system as the INO delivery method.

\section{Plan-Do-Study-Act (PDSA) Cycles}

Using the model for improvement methodology, we evaluated institutional use of INO and created a pathway to reduce waste. The project team began analyzing hospitalwide INO use in January 2018. Initiation criteria for INO therapy was left to the treating team with a starting dose of $20 \mathrm{ppm}$. Prior to project initiation, there was no standard for weaning or cessation of INO. The project team came to

\section{QUICK LOOK}

\section{Current knowledge}

Inhaled nitric oxide is an expensive therapy used in neonatal ICUs, pediatric ICUs, and cardiovascular ICUs. While some patients show rapid improvement with therapy, many are treated longer than necessary. Previous quality improvement studies have reported success implementing nitric oxide weaning protocols within an ICU.

\section{What this paper contributes to our knowledge}

A hospital-wide, inhaled nitric oxide implementation and weaning protocol utilized by all 3 ICUs in a large, quaternary pediatric academic medical center was found to be safe for patient care, translatable across separate ICUs, and resulted in a profound decrease in the amount of nitric oxide used by the hospital.

2 conclusions regarding our institutional use of INO. First, the largest opportunity to reduce unnecessary INO use was related to inconsistencies in the duration and cessation of INO therapy, as weaning was variable with regard to interval and dose. Second, our patient selection for treatment with INO was appropriate, and further efforts to improve this would be of low value. This determination was made on the basis that there are few true indications for INO therapy. Regarding the pediatric ICU population, the PALICC guidelines describe INO therapy as a supplemental therapy for refractory hypoxemia that is not routinely recommended. ${ }^{14}$ The neonatal ICU uses INO therapy for new patients with congenital diaphragmatic hernia or severe refractory hypoxemia due to meconium aspiration or persistent pulmonary hypertension of the newborn. The cardiac ICU uses INO primarily for acute treatment of pulmonary hypertension related to underlying congenital heart disease. The project leadership team, which included members from all 3 ICUs, concluded that the decision to initiate INO therapy was not a variable that required further standardization.

Figure 1 shows the key driver diagram for this project. The elements of the project were: (1) start INO therapy consistently at $20 \mathrm{ppm}$; (2) institute objective criteria to initiate weaning; (3) follow a set weaning protocol for interval and dose of INO; and (4) have a definitive plan for discontinuing INO therapy with criteria for re-initiating if the subject does not tolerate discontinuation.

PDSA Cycle 1. The first PDSA cycle was focused on protocol development, staff education, and protocol initiation. Starting in July 2018, relevant literature was reviewed to identify safe and effective practices for INO weaning across neonatal and pediatric populations. ${ }^{10,15,16}$ Subjects who 


\section{RT-Driven Protocol to REDUCE UnNECESSARy INO USE}

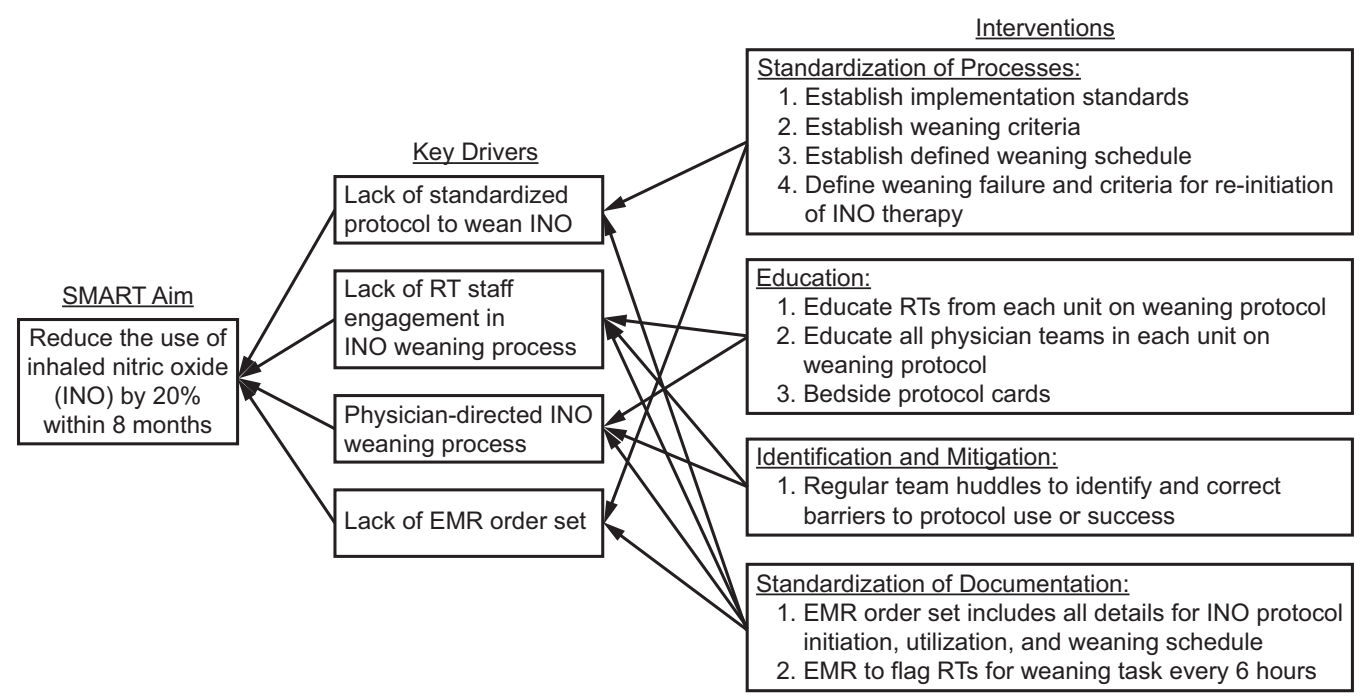

Fig. 1. Key drivers. INO = inhaled nitric oxide, $\mathrm{RT}=$ respiratory therapist, $\mathrm{EMR}=$ electronic medical record.

were started on INO and had no perceived benefit could be taken off therapy per clinician discretion and did not necessarily have to follow the weaning protocol. For subjects who had a perceived benefit and remained on INO therapy, criteria to wean were defined as $\mathrm{F}_{\mathrm{IO}_{2}} \leq 0.60$ and pulse oximetry meeting subject-specific goals that included inherent flexibility to accommodate for cyanotic cardiac lesions. Subjects had cardiopulmonary monitoring parameters (ie, pulse oximetry, heart rate, and systolic, diastolic, and mean arterial blood pressures) established as part of their general ICU care. Subjects were screened every $6 \mathrm{~h}$; if criteria were met, then weaning occurred in a stepwise approach (at 12:00 AM, 6:00 AM, 12:00 PM, and 6:00 PM) as follows: 15 ppm, 10 ppm, 5 ppm, 2.5 ppm, and off (Fig. 2). Criteria for wean failure were a decrease in pulse oximetry below goal for $>10$ min despite increasing $\mathrm{F}_{\mathrm{IO}_{2}}$, a decrease in arterial pressures below goal, or an increase in central venous/atrial pressure or pulmonary artery pressures (if applicable) for $>$ $10 \mathrm{~min}$ in response to a change in INO dose. If weaning failure occurred, the subject was placed back on the previously tolerated dose and not necessarily the starting dose of $20 \mathrm{ppm}$. If failure occurred while weaning to off, INO was resumed at $5 \mathrm{ppm}$.

Once the protocol was agreed upon by the project team, it was disseminated to the intensive care physicians via short educational workshops followed by updates at regular intervals (ie, every 1-2 months). Educational workshops were also done for the respiratory therapy groups in each unit. Once education and small-scale testing were completed, the protocol was initiated in October 2018.

PDSA Cycle 2. An audit of the weaning pathway from October and November 2018 revealed that the majority of failed opportunities were due to poor awareness of the details of the protocol among the clinician and respiratory

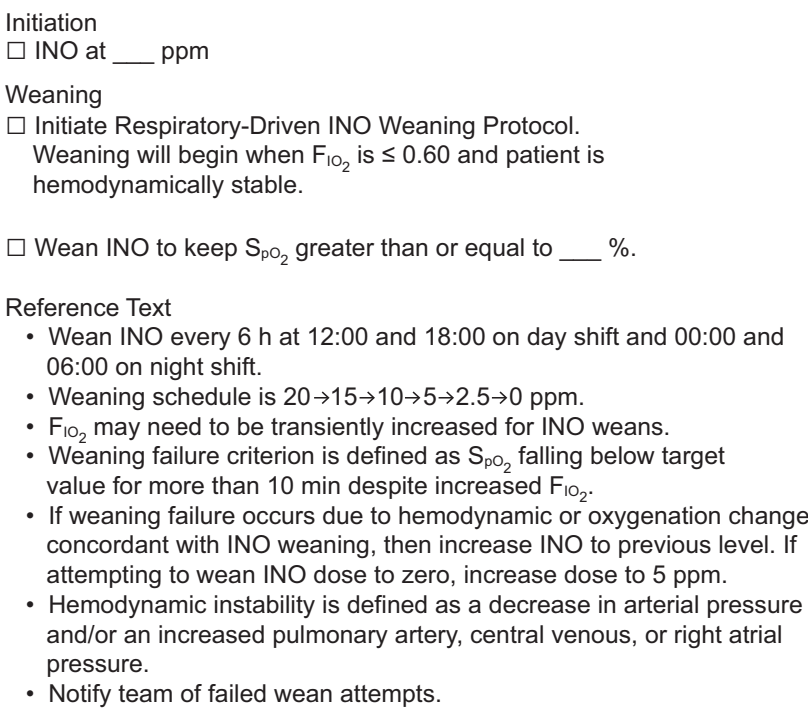

$\square$ Wean INO to keep $\mathrm{S}_{\mathrm{pO}_{2}}$ greater than or equal to $\%$.

Reference Text

- Wean INO every $6 \mathrm{~h}$ at $12: 00$ and 18:00 on day shift and 00:00 and 06:00 on night shift.

- Weaning schedule is $20 \rightarrow 15 \rightarrow 10 \rightarrow 5 \rightarrow 2.5 \rightarrow 0 \mathrm{ppm}$

- $\mathrm{F}_{\mathrm{IO}_{2}}$ may need to be transiently increased for INO weans.

- Weaning failure criterion is defined as $\mathrm{S}_{\mathrm{pO}_{2}}$ falling below target value for more than 10 min despite increased $\mathrm{F}_{\mathrm{IO}_{2}}$.

- If weaning failure occurs due to hemodynamic or oxygenation change concordant with INO weaning, then increase INO to previous level. If attempting to wean INO dose to zero, increase dose to $5 \mathrm{ppm}$.

- Hemodynamic instability is defined as a decrease in arterial pressure and/or an increased pulmonary artery, central venous, or right atrial pressure.

- Notify team of failed wean attempts.

Fig. 2. Weaning protocol. INO = inhaled nitric oxide.

therapy teams (Fig. 3). The project team noted that when more experienced respiratory therapists, or those who were directly involved in the protocol's development, were the bedside therapist, there was a higher level of compliance with the protocol. The same was true for the medical teams, with higher compliance by those who were directly involved with the protocol development. Compliance also seemed higher initially in the pediatric ICU and neonatal ICU than in the cardiac ICU. The project team met to discuss ideas to address these barriers. A laminated bedside card that contained the weaning criteria and weaning schedule was placed on each INO tank as a reminder to the bedside nurse, clinician team, and primarily the respiratory therapist that the subject who is receiving INO should be on the weaning protocol (Fig. 2). These cards were in open 


\section{RT-Driven Protocol to REDUCE UnNECESSARy INO USE}

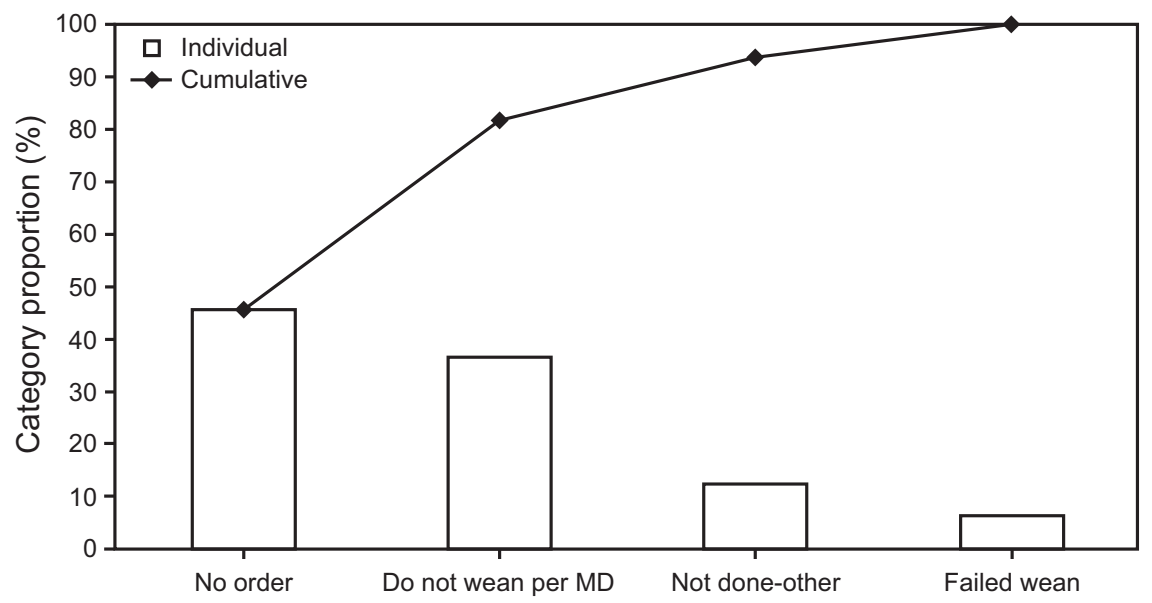

Fig. 3. Reasons for failed weaning opportunities.

view of the respiratory therapist at the time of INO initiation as a level of reliability 1 intervention. Informal post-intervention feedback was that these cards were helpful for the respiratory therapists as a reminder both that the subject should be on the protocol and how the protocol was to be conducted.

PDSA Cycle 3. In February 2019, we implemented a weekly huddle on Tuesday mornings at 8:00 AM, during which a representative from the project team would meet with on-service physicians as well as respiratory therapy representatives from the neonatal ICU, pediatric ICU, and cardiac ICU teams. During this brief huddle, the team discussed subjects who were currently on INO therapy, if the weaning protocol had been implemented, and barriers for its implementation in patients who were not on the protocol. This huddle served to provide education for the representatives as to the details and goals of the protocol and to inform the project team what barriers were being encountered.

PDSA Cycle 4. The INO order set had been built during the planning phase prior to the protocol implementation. During implementation, we realized a pitfall in the INO order set, in that when the INO was ordered it was not automatically linked with an order to initiate the weaning protocol. There was a lack of awareness among the medical providers about the need to simultaneously order the INO medication and the weaning protocol. Contemporaneous with PDSA cycle 3, PDSA cycle 4 was a designed level of reliability 2 intervention linking the ordering of INO to the order to start the INO weaning protocol in the electronic medical record. This eliminated provider error and oversight.

\section{Statistical Analysis}

Pre-implementation data were obtained retrospectively from January to September 2018, and post-implementation data were obtained prospectively through manual electronic chart review from October 2018 to August 2019. Project data were collected and managed using REDCap, ${ }^{17,18}$ a database electronic data capture tool hosted at Indiana University, and included subjects' total hours of INO use, primary diagnosis necessitating INO therapy, ICU in which the subject received care, and sildenafil use. Total monthly hospital hours of INO was used as the primary outcome measure. To account for varying numbers of subjects using INO per month, median hourly use per subject (evaluated in groups of 7) was used as a secondary outcome measure. The study goal was a reduction of INO total hospital use by $20 \%$ within 8 months of protocol implementation. Both outcome measures were evaluated using statistical process control charts created using the QI Macros add-in for Excel 2018 (KnowWare International, Denver, Colorado). The upper control limit and lower control limit were calculated as 3 standard deviations above and below the center line. A shift in the center line was performed when there were 8 consecutive points above or below the center line. New sildenafil dosing was tabulated for pre- and post-INO weaning protocol implementation as a balancing measure, and the proportions were compared using a chi-square test. Project updates were given at regular intervals to different ICU quality and safety committees, as well as during physician faculty meetings.

\section{Results}

Ninety-seven subjects were included in the pre-implementation analysis. The protocol was implemented and data were collected on 110 subjects. Table 1 shows the breakdown of subject demographics, diagnoses, and subject location. Following protocol implementation, mean total hospital INO use decreased from $1,515 \mathrm{~h} /$ month to 930 h/month (Fig. 4). The per-subject mean INO use decreased from $88 \mathrm{~h} /$ subject to $50 \mathrm{~h} /$ subject (Fig. 5). There was a period of special-cause variation in the median use group that 


\section{RT-Driven Protocol to REDUCE UnNECESSARy INO USE}

occurred at the end of August 2018. Upon review of the subjects at that time, 3 subjects were admitted to the neonatal ICU within several days of each other with severe congenital diaphragmatic hernia. Contemporaneously, the cardiovascular ICU had 2 subjects with severe pulmonary hypertension. All 5 of these subjects had prolonged use of INO. The total INO hours and number of subjects receiving INO did not meet special-cause variation during this time.

Safety data were obtained regarding mortality and hospital stay both prior to protocol implementation and following protocol implementation. The median length of hospital stay prior to protocol implementation was $35 \mathrm{~d}$, and after protocol implementation was $36.5 \mathrm{~d}$, which was not significantly different $(P=.87)$. The mortality rate in our population prior to protocol implementation was $18.56 \%$ (18 of 97), and after protocol implementation this

Table 1. Subject Demographics, Unit Distribution, and Primary Diagnosis

\begin{tabular}{lr}
\hline \hline Age, months & $0.5(0-15)$ \\
Gender & \\
Female & $93(45)$ \\
Male & $114(55)$ \\
Unit & \\
Cardiovascular ICU & $85(41)$ \\
Neonatal ICU & $72(35)$ \\
Pediatric ICU & $50(24)$ \\
Primary diagnosis & \\
Congenital heart disease & $90(44)$ \\
ARDS & $34(16)$ \\
Persistent pulmonary hypertension of the newborn & $30(15)$ \\
Neonatal respiratory distress syndrome & $13(6)$ \\
Bronchopulmonary dysplasia & $11(5)$ \\
Meconium aspiration syndrome & $11(5)$ \\
Congenital diaphragmatic hernia & $10(5)$ \\
Other & $8(4)$
\end{tabular}

Data are presented as $n$ (\%) except age, which is presented as median (interquartile range). $N=$ 207 subjects. was $18.18 \%$ (20 of 110), which was not significantly different $(P=.99)$. These comparisons indicate that no increase in mortality or hospital stay was seen following protocol implementation.

The monthly number of subjects receiving INO did not change over the course of the project (see the supplementary materials at http://www.rcjournal.com). Based on our results, the actual reduction of total hospital INO use was $39 \%$ within 9 months of protocol implementation. When adjusting for the total number of subjects utilizing INO, the actual reduction of INO hours of use per subject was $43 \%$. Regarding the balancing measure, new sildenafil use did not change after protocol implementation (18\% [18 of 98 subjects] compared to $11 \%$ [12 of 109 subjects], $P=.27$ ), respectively.

During the time of this study, the hospital charge was $\$ 130$ per hour of INO use. Based on the pre-implementation data, a total charge of $\$ 196,950$ per month was calculated for INO use. Using the post-implementation data, a total charge of $\$ 120,900$ per month was obtained. Extrapolating this data to a yearly amount results in a yearly hospital charge savings of $\$ 912,600$. At the per-subject level, the average charge prior to protocol implementation was $\$ 11,440$ compared to $\$ 6,500$ post-implementation, resulting in an average savings of $\$ 4,940$ per subject.

\section{Discussion}

The specific aim of this project was to decrease the utilization of INO in our institution by $20 \%$ within 8 months of protocol initiation. We ultimately achieved a decrease of $39 \%$ within 9 months of protocol initiation. At the 8-month mark, we lacked the statistical ability to shift our center line, thus we stretched our data collection to 9 months. To our knowledge, this is the first standardized INO weaning protocol to be applied to all of the ICUs in one hospital. The creation of this protocol had unique challenges inherent to such a widespread application. The patient populations

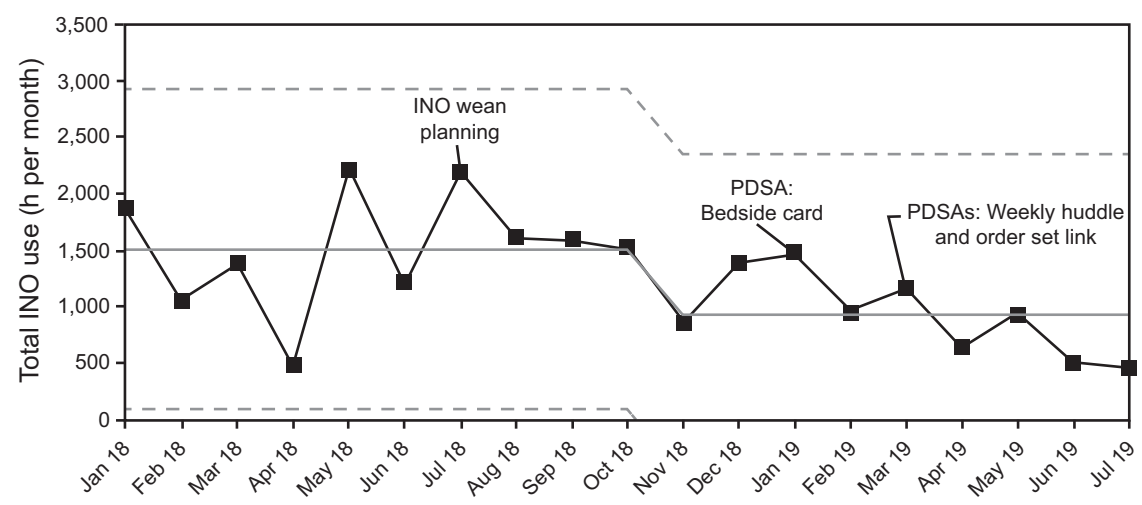

Fig. 4. Hospital-wide INO use. Gray line denotes average, and dashed lines show upper and lower confidence limits, respectively. INO = inhaled nitric oxide; PDSA = plan-do-study-act. 


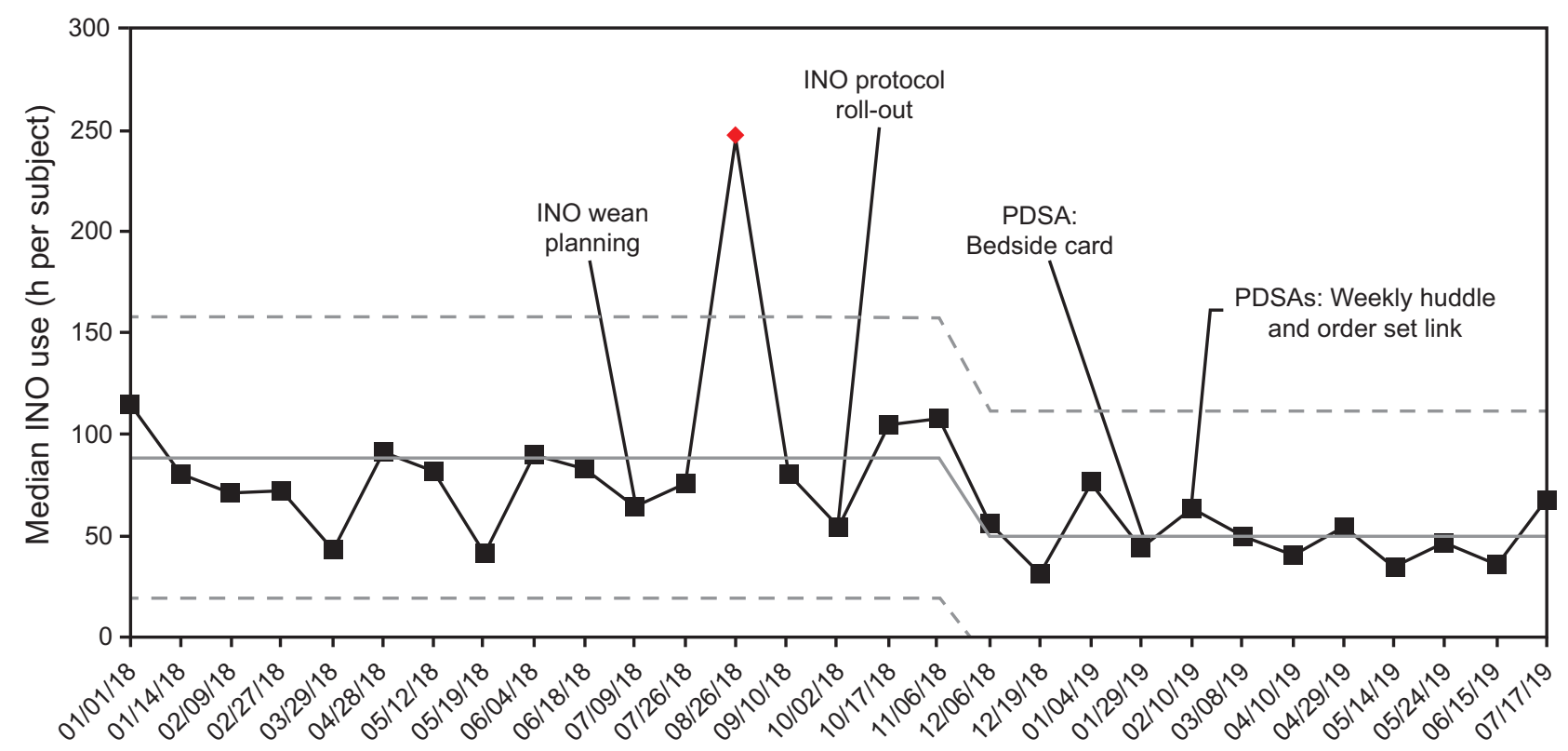

Fig. 5. Median use (in hours per subject). Gray line denotes average, and dashed lines show upper and lower confidence limits, respectively. The red diamond represents a value outside of the upper or lower confidence levels. INO = inhaled nitric oxide; PDSA = plan-do-study-act.

who are typical recipients of INO varied greatly across the ICUs. Neonatologists treating patients with severe bronchopulmonary dysplasia, congenital diaphragmatic hernias, and pulmonary hypoplasia had a culture and personal experience in utilizing INO that was slightly different from that of the general pediatric intensivists who utilized INO primarily for patients with severe ARDS. Adding the pediatric cardiac intensivists who utilized INO mainly for pulmonary vasodilation in patients with congenital cardiac lesions or pulmonary vascular abnormalities brought another layer of complexity. This heterogeneity added complexity to the creation and design of the protocol and precipitated several face-to-face meetings with unit leadership to identify the needs of each separate unit and establish buy-in by unit leadership. Even with these efforts in place prior to protocol implementation, there were several steps required to improve adherence to the process.

As modern health care provides increasing numbers and varieties of diagnostic tests and therapeutic interventions, there is also increasing risk of overuse ${ }^{19}$ Overuse of INO is not only an expensive waste of hospital resources, but it may also adversely impact patient outcomes. Our goal was not to limit the amount of medication provided to patients who required or benefited from INO, but to decrease the amount provided to patients who no longer needed it.

The success of the protocol was demonstrated by the profound reduction in total hospital use, as well as in per subject use. The cost avoidance was nearly a million dollars per year. If similar results could be seen in other institutions utilizing this protocol, the widespread cost-savings could be beneficial to national and global health care systems as we seek to decrease the large burden of health care-associated costs. The reduction in practice variation due to instituting a protocolized weaning method led to a more efficient process than deciding on a case-by-case basis. ${ }^{9-11}$ The dramatic scale of cost reduction seen in this study is likely due to the scope of the intervention being hospitalwide, as opposed to being implemented in individual units as seen in prior studies. ${ }^{9,11,13}$ Physician providers have a very wide spectrum of responsibilities throughout a hospital workday, and this practice is often amplified in an ICU setting. Allowing respiratory therapists to take ownership of this process and integrate it seamlessly into their daily workflow is likely what made the largest contribution to the success of the protocol. Previous studies have shown that respiratory therapist-driven protocols and interventions can contribute significantly to patient safety and the flow of patients in an ICU. ${ }^{19,20}$ This provides another example of how empowering the entire patient care team can lead to significant improvement in the care of individual patients.

One concern that we had was the potential for trading decreased use of INO for increased use of alternative pulmonary vasodilator therapies. Our institutional preference as a first-line therapy is phosphodiesterase inhibitor (sildenafil), another expensive and potentially toxic therapy. For this reason, we chose sildenafil use as our balancing measure. The general practice for sildenafil use in our institution is variable. The majority of patients receiving it are cardiac ICU patients who have evidence of severe pulmonary hypertension. However, there is currently no standard in our institution as to which patients receive it. It is decided on a case-by-case basis with input from the 


\section{RT-Driven Protocol to REDUCE UnNECESSARy INO USE}

institutional pulmonary hypertension team. While the percentage of subjects being started on sildenafil was lower post-protocol, the use of sildenafil was not significantly different in pre- versus post-protocol analysis. It is possible that the increased emphasis on weaning subjects from INO therapy actually led to fewer subjects requiring it for a prolonged course, and this may have led to fewer subjects being started on sildenafil for inability to wean INO. Our institutional use of alternative pulmonary vasodilator therapies such as inhaled, intravenous, or subcutaneous prostaglandins and endothelin-1 antagonists is minimal.

There are several limitations to this study. The first is that while multiple ICUs were involved throughout the hospital, this is a single-center study that may have center-specific practices that were more or less responsive to the implemented changes than would be seen at other institutions. Another potential limitation is that although our neonatal ICU is a completely separate unit staffed by neonatologists and unit-specific respiratory therapists, our pediatric ICU and cardiac ICU are closely connected, with attending physicians all under the same division and respiratory therapists from a single pool staffing both the pediatric ICU and cardiac ICU. This made the education of staff and the implementation of the protocol easier than if there were 3 separate physician and respiratory therapy groups.

\section{Conclusions}

A hospital-wide, standardized, respiratory therapistdriven protocol for the use and weaning of INO was effectively implemented, resulting in a decrease in unnecessary INO use. This represents a potentially substantial opportunity for other centers to utilize a similar protocol to achieve a safe and effective means to standardize the use and discontinuation of INO therapy.

\section{REFERENCES}

1. Higenbottam T, Siddons T, Demoncheaux E. A therapeutic role for chronic inhaled nitric oxide? Lancet 2000;356(9228):446-447.

2. Van Meurs KP, Wright LL, Ehrenkranz RA, Lemons JA, Ball MB, Poole WK, et al. Inhaled nitric oxide for premature infants with severe respiratory failure. N Engl J Med 2005;353(1):13-22.

3. Golombek SG, Young JN. Efficacy of inhaled nitric oxide for hypoxic respiratory failure in term and late preterm infants by baseline severity of illness: a pooled analysis of three clinical trials. Clin Ther 2010;32 (5):939-948.
4. Adhikari NK, Dellinger RP, Lundin S, Payen D, Vallet B, Gerlach H, et al. Inhaled nitric oxide does not reduce mortality in patients with acute respiratory distress syndrome regardless of severity: systematic review and meta-analysis. Crit Care Med 2014;42(2):404-412.

5. Hasan SU, Potenziano J, Konduri GG, Perez JA, Van Meurs KP, Walker MW, et al. Effect of inhaled nitric oxide on survival without bronchopulmonary dysplasia in preterm infants: a randomized clinical trial. JAMA Pediatr 2017;171(11):1081-1089.

6. Stewart DL, Vogel PA, Jarrett B, Potenziano J. Effect of inhaled nitric oxide on oxygen therapy, mechanical ventilation, and hypoxic respiratory failure. Minerva Pediatrica 2018;70(1):51-58.

7. Dowell JC, Thomas NJ, Yehya N. Association of response to inhaled nitric oxide and duration of mechanical ventilation in pediatric acute respiratory distress syndrome. Pediatric Crit Care Med 2017;18(11): 1019-1026.

8. Weinberger B, Laskin DL, Heck DE, Laskin JD. The toxicology of inhaled nitric oxide. Toxicol Sci 2001;59(1):5-16.

9. Todd Tzanetos DR, Housley JJ, Barr FE, May WL, Landers CD. Implementation of an inhaled nitric oxide protocol decreases direct cost associated with its use. Respir Care 2015;60(5):644-650.

10. Aly H, Sahni R, Wung JT. Weaning strategy with inhaled nitric oxide treatment in persistent pulmonary hypertension of the newborn. Arch Dis Child Fetal Neonatal Ed 1997;76(2):F118-122.

11. Simsic JM, Harrison S, Evans L, McClead R, Teske D. Reducing variation in the use of inhaled nitric oxide. Pediatrics 2014;133(6):e1753e1758.

12. Elmekkawi A, More K, Shea J, Sperling C, Da Silva Z, Finelli M, et al. Impact of stewardship on inhaled nitric oxide utilization in a neonatal ICU. Hospital Pediatrics 2016;6(10):607-615.

13. Hughes Driscoll CA, Davis NL, Miles M, El-Metwally D. A quality improvement project to improve evidence-based inhaled nitric oxide use. Respir Care 2018;63(1):20-27.

14. Cheifetz IM. Pediatric ARDS. Respir Care 2017;62(6):718-731.

15. Ware AM, Golombek SG. Weaning of inhaled nitric oxide: is there a best strategy? J Pediatr Neonat Individual Med 2015;4(1):e040124.

16. Kageyama K, Shime N, Hirose M, Hiramatsu N, Ashida H, Hashimoto S. Factors contributing to successful discontinuation from inhaled nitric oxide therapy in pediatric patients after congenital cardiac surgery. Pediatric Crit Care Med 2004;5(4):351-355.

17. Harris PA, Taylor R, Thielke R, Payne J, Gonzalez N, Conde JG. Research electronic data capture (REDCap)-a metadata-driven methodology and workflow process for providing translational research informatics support. J Biomed Inform 2009;42(2):377-381.

18. Harris PA, Taylor R, Minor BL, Elliott V, Fernandez M, O'Neal L, et al. The REDCap consortium: building an international community of software platform partners. J Biomed Inform 2019;95:103208.

19. Maue DK, Tori AJ, Beardsley AL, Krupp NL, Hole AJ, Moser EA, et al. Implementing a respiratory therapist-driven continuous albuterol weaning protocol in the pediatric ICU. Respir Care 2019;64(11):13581365.

20. Abu-Sultaneh S, Hole AJ, Tori AJ, Benneyworth BD, Lutfi R, Mastropietro CW. An interprofessional quality improvement initiative to standardize pediatric extubation readiness assessment. Pediatric Crit Care Med 2017;18(10):e463-e471.

This article is approved for Continuing Respiratory Care Education credit. For information and to obtain your CRCE

(free to AARC members) visit

www.rcjournal.com

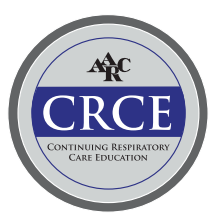

